\title{
Proceeding
}

Supplementary Issue: Spring Conferences of Sports Science. Costa Blanca Sports Science Week, 26-28 April 2018. Calpe. Alicante, Spain

\section{Effects of a program of vigorous-to-intense physical activity in triglycerides and glucose in 3- to 16-year-old schoolchildren}

FRANCISCO JOSÉ BORREGO BALSALOBRE $४$, GUILLERMO FELIPE LÓPEZ SÁNCHEZ, ARTURO DÍAZ SUÁREZ

Faculty of Sports Sciences, University of Murcia, Spain

\begin{abstract}
The aim of this study was to determine if there is a direct association between an intervention program through vigorous-to-intense physical activity and the improvement of certain values of the lipid profile through a fasting analysis of triglycerides and glucose. The sample was composed of 116 schoolchildren between the ages of 3 and 16 (52 boys and 64 girls). A biochemical analysis was used to evaluate the health parameters through a blood draw carried out by the medical staff of the Murcian Health Department. The intervention was carried out 3 times per week during 12 weeks. Through games, rule modification and variations of these, it was favored the use of short repetitions of vigorous and high intensity in races, throws and jumps. The statistical analysis was carried out with the statistical package SPSS 15.0.1 for Windows 8 Pro. It was found an association between the program and the improvement in glucose levels, but not in triglycerides. Furthermore, the improvements were equally significant in males and females of Primary and Secondary Education, but not in Pre-School Education. Key words: SCHOOL AGE, INTENSE PHYSICAL ACTIVITY, LIPID PROFILE, HEALTH.
\end{abstract}

\section{Cite this article as:}

Borrego Balsalobre, F., López Sánchez, G., \& Díaz Suárez, A. (2018). Effects of a program of vigorousto-intense physical activity in triglycerides and glucose in 3-to 16-year-old schoolchildren. Journal of Human Sport and Exercise, 13(2proc), S432-S444. doi:https://doi.org/10.14198/jhse.2018.13.Proc2.27

Corresponding author. Faculty of Sports Sciences, University of Murcia, Spain.

E-mail: franborrego@um.es

Supplementary Issue: Spring Conferences of Sports Science. Costa Blanca Sports Science Week, 26-28 April 2018. Calpe. Alicante, Spain.

JOURNAL OF HUMAN SPORT \& EXERCISE ISSN 1988-5202

(c) Faculty of Education. University of Alicante

doi: 10.14198/jhse.2018.13.Proc2.27

S432 | 2018 | Proc2 | VOLUME 13

(C) 2018 University of Alicante 


\section{INTRODUCTION}

Health is one of the most spoken about subjects worldwide; this is due to the interest it awakens in our society. To a large extent, a great number of deaths can be associated directly or indirectly to a poor level of health found in the habits and lifestyle of individuals. Because of this, many authors have been presenting in their studies that the modification of these habits to healthier and better conducts regarding hygiene, nutrition and physical activity, will contribute towards a better quality of life and less healthcare expenses (Ries, Voorhees, Gittelsohn, Roche \& Astone, 2008). For that matter, other research has analysed the effectiveness of interventions promoting physical activity to children and teenagers, highlighting the lack of quality, in terms of effectiveness, in the conclusions of these studies (van Sluijs, van Poppel, \& van Mechelen, 2004). Along the same lines, other authors have analysed the effects of interventions in randomized controlled trials, including in their treatment coping strategies for overweight children and teenagers, the use of pharmaceuticals, physical activity and/or dieting, highlighting the lack of evidence in terms of the efficiency of these treatments in the long-term (McGovern et al., 2008).

From here, it is easy to begin understanding the direct relationship between the level of achieved physical activity and the health of the schoolchildren, as well as the interrelationship which the following concepts will have: Physical Activity, Fitness and Health (Shephard \& Bouchard, 1995).

\section{Physical fitness and health at school age}

Physical fitness can be defined as the individual's physical and assessable attributes which are connected to their capacity to do physical activities (Caspersen, Powell, \& Christenson, 1985).

However, there are a lot of elements which affect this capacity to do physical activities. Sedentariness and a low level of physical fitness, among others, are determining factors in the appearance of certain diseases which are of great concern to society nowadays, as is the case of obesity (Moliner-Urdiales et al., 2010; Ochoa et al., 2007). According to previous research, which has been developed in the recent past, aerobic capacity and muscle strength are important indicators and predictors of the presence of illness and mortality due to cardiovascular risk (Carnethon et al., 2003; Myers et al., 2002). Building on this, it is important to mention that the beginning of this type of illnesses, which in most cases start in adulthood, tend to show their first signs in childhood and adolescence (McGill, McMahan, Zieske, et al., 2000), finding in some of these cases risk factors of cardiovascular disease (McGill, McMahan, Herdericke, et al., 2000). Some of them can predict future morbidity and mortality, as is the case of childhood overweight (Must, Jacques, Dallal, Bajema, \& Dietz, 1992).

Along these lines, some authors have established in their research that the role of a low level of fitness as a cardiovascular risk factor is higher than other well-established factors, such as dyslipidemia, hypertension or obesity (McGill, 1990).

The study of the above mentioned factors during the crucial phase of childhood and adolescence is, thus, key for the diagnosis and prevention of conditions associated to cardiovascular disease in adults. For that matter, many cross-sectional studies have shown the relationship between the level of physical fitness and other cardiovascular risk factors during childhood and adolescence (Ekelund et al., 2001). Likewise, important longitudinal studies have determined that the level of physical fitness which is had in adulthood, along with the presence of other conventional cardiovascular risk factors (hypercholesterolemia, hypertension, etc.), are conditioned by the level of physical fitness which is had in childhood and adolescence. 
Nevertheless, the concepts associated with the definition of the physical fitness are multiple, being this the most important matter with which this study is concerned, and which is directly associated with the term health (Caspersen, et al., 1985). Because of this, the quantity and type of physical activity which is done will determine the level of physical fitness, at the same time, this level will determine the type of activity which can be done (Shephard \& Bouchard, 1994). This line of research develops and suggests a definition which characterises physical fitness as (Pate, Corbin, Simonsmorton, \& Ross, 1987): the ability to do vigorous activities daily and the manifestation of features and capacities associated with the low risk of premature occurrence of hypokinetic diseases.

As a result, it is important to assess the benefits which physical activity can have in human beings, seeing as most widespread and studied those connected to adaptations and effects which this has on the cardiovascular system, and considering the positive influence of physical activity in the prevention and recovery from coronary diseases as one of the most important findings (Morris, Pollard, Everitt, Chave, \& Semmence, 1980). In fact, the World Health Organization (from now on WHO) has indicated physical inactivity as an important risk factor in heart diseases which have to be prevented by a series of measures. Taking these measures and assessing future cardiovascular risk in the earliest way possible, through an evaluation and early action, will help prevent the appearance of certain diseases from childhood or adolescence.

\section{Health parameters in the school age and obesity}

Obesity is a chronic disease defined as an excess in body fat and excess weight in relation to size, which produces cardiovascular problems in the subject (Damasceno et al., 2009). It is considered a chronic disease by the WHO because it is maintained over time and is associated with the metabolic insulin resistance syndrome (MIRS), which in the future determines a higher risk of diabetes mellitus type 2 (DM2), arterial hypertension (AH) and ischemic cardiovascular diseases (ICD) (Dietz, 2001; Fagot-Campana et al., 2000). It is a topic of interest and of worldwide concern because it is considered a disease of epidemiological proportions not only in the United States but in many other countries across the globe (Goran, 2001). The incidence rates for this disease rise dramatically each year, being very high in Spain during these last few years (Dumith \& Farias, 2010; Giralt et al., 2011; Ochoa et al., 2007).

These authors establish an unsuitable diet, habits and lifestyle as the causes for excessive fat storage in the fat tissues; along with genetic factors which also play an important part in this. Along these lines, Seidell and Flegal (1997) specify the imbalance between calorie intake and its subsequent energy consumption as the main cause for the emergence of obesity in humans.

Furthermore, it is important to mention that problems with excess weight and obesity have only gained world recognition in the last ten years, by comparison to what some of the other main concerns of the human race, such as malnutrition, underweight and infectious diseases, have needed for many years. But obesity is not just a disease in itself, it is also a medical disorder which can lead to many comorbidities (Haslam \& James, 2005).

Many of obesity's comorbidities can be seen in what is known as metabolic syndrome or central obesity. Nowadays, up to $30 \%$ of middle-aged people and $60 \%$ of people in their seventies, in the most developed countries, have several characteristics of metabolic syndrome. Some authors underscore the importance of central obesity because it represents a risk factor which influences early hyperinsulinemia. It is not a matter of just one disease but of a combination of problems which can appear either simultaneously or sequentially in an individual, caused by a combination of genetic and environmental factors and connected to a lifestyle 
in which insuline resistance is considered a fundamental pathogenic component. Certain authors have determined the following as components of the metabolic syndrome (Cleeman et al., 2001; Haslam \& James, 2005): abdominal obesity, high triglycerides, high cholesterol, artherial hypertension and fasting hyperglycemia.

If three or more of these risk factors coexist, it should be considered as metabolic syndrome. Because of this, a lot of studies agree that blood pressure control along with control of triglyceride, cholesterol and blood sugar levels can facilitate the knowledge and definition of the state of excess weight and obesity (RomeroVelarde, et al., 2007). But these are not the only indicators of this state, as far as some other authors have established anthropometry and the BMI (Body Mass Index) as the most recommended and most widely used to carry out epidemiological studies (Eaton et al., 2006; Grunbaum et al., 2002), in concordance with what has been established by the WHO.

\section{Aims of the study}

- Determine if a vigorous to intense physical activity program impinges on the blood levels of triglycerides and glucose in school children of ages 3 to 16 .

- Determine if gender and school year affect the possible differences which may be obtained in the health parameter values of 3-to 16-year-old schoolchildren.

\section{MATERIAL AND METHODS}

\section{Characteristics of the population and sample}

The current study was a pilot study carried out on children and teenagers ages 3 to 16 of all ages and school years. An attempt was made to make it as equitable as possible in terms of gender. The sample was not probabilistic and was random according to a serie of criteria of inclusion and exclusion. The total was $n=116$ (52 boys and 64 girls). The inclusion criteria established that they be within the school years of $3^{\text {rd }}$ year of Pre-School and $4^{\text {th }}$ year of middle school and that they bring duly completed informed consent. The only exclusion criteria established was in the case of suffering any disease which could be a risk when carrying out the foreseen tests, due to the intensity of them. Thus, within the parameters of the stages in which the study was to be centered and the population of 1800 students at our disposal, the selection of the definitive sample was completely at random.

\section{Procedure and design}

The study was carried out doing a quantitative study with a transversal prescriptive design following the ethical standards recognised by the Declaration of Helsinki (Hong-Kong revision, September of 1989) and according to the recommendations of Good Clinical Practice by the CEE (article 111/3976/88 of July of 1990) and the current Spanish legislation which regulates clinical research on humans (Royal Decree 561/ 1993 on clinical essays).

In order to set the study in motion at the centre, first of all the director of the centre was informed, with the previous authorization of the department of Physical Education. After this, all the premises, criteria, conditions and development of the research were presented in 1800 letters and informed consent to the parents or tutors of the children and teenagers and a meeting in the centre was held in the presence of the staff which was to intervene in the measurement of the parameters.

Previous to the carrying out of the study, training tests were done on the researchers involved in the project to standardise, validate, and study the reliability of the measure. 
The preparatory data collection or pre-test was carried out upon returning from the Christmas holidays during the first two weeks of January, through a blood test, in the health centre which was next to the school, by health staff from the Murcian Health Department under the rules of the agreement established between the University of Murcia and the Murcian Health Department. The acting protocol consisted in making appointments with 15 students a day within the hours of $09: 00$ and 10:30 through an information circular sent to the parents and prior agreement with the health staff. An attempt was made to gather the students by age group, even though the appointments were made every 5 minutes. The students which could not be accompanied by the parents or relatives, since the pretest was carried out during school hours, were accompanied by the research staff with the consequential duly signed informed consent. In both the informative meeting before and the circular it was insisted that students come to the test with an empty stomach, in order to not alter the results. At all times it was carried out guaranteeing the privacy of the participants.

After this, a 12-week physical activity intervention was carried out during the recess of the students, taking advantage that it was at different times for Pre-School, Primary and Seconday Education to distribute the groups and take advantage of the spaces. A couple weeks after the Easter holidays, the final data collection or posttest was carried out following the same procedure as the pretest.

\section{Variables and materials used}

Instruments and evaluation of the health parameters

A biochemical analysis was carried out on the blood tests performed by the health staff from the Murcian Health Department in the laboratories of the Hospital Virgen de la Arrixaca using automatised equipment, along with a subsequent analysis by the appropriate practitioner which included fasting basal glycaemia and the lipid profiles in blood through triglycerides.

\section{The vigorous-to-intense physical activity intervention program}

Spatial organization and timetable and practice time

Each session lasted 15 minutes, divided in 10 minutes of real time and 5 for organizing, explaining the game and changing the corresponding groups.

The intervention was carried out during 12 weeks during recess every Monday, Wednesday and Friday. To do so, the activity was divided into three groups, since the timetables of each was different and the age groups made it so that the activities had to be adapted to each group, which is why each group was divided into subgroups of 2 school years each, with the exception of 3-year-old children who did it alone.

The intensity of the practice

The intensity which was aimed for at all time was from vigorous to intense, taking into consideration that we were dealing with children and teenagers and that, in order to motivate them, it was necessary to disguise the exercises through games moving away from the traditional and analytical. Thus, a battery of 10 games was developed to avoid falling into monotony, putting a different one into practice each day and starting again with the first game after 10 sessions. Each game had two or three variations which over the 12 weeks were introduced in order to maintain the intensity of participation. All of the games were set up in adapted spaces and with the necessary rules in order to achieve the appearance of consecutive races and short persecutions at a high intensity. In this way an intervallic participation was achieved with these intensities. In addition, in order to complete the intervention, the appearance of jumps and throws was encouraged to develop both strength and endurance with some games. If it was seen that the intensity of the game decreased, a mobile 
was introduced quickly, a small rule or modification or one of the researchers joined the game in order to maintain the rhythm of the practice.

In this regard, it was necessary to participate mainly in the Pre-school group since from the battery of 10 games, those of complex organization had to be discarded, having to modify the rules of some of them simplifying their organization as much as possible reaching the point that in most occasions the researchers had to incorporate themselves within the game and ended up becoming subjects of the persecutions.

\section{Statistical analysis}

The statistical comparison tests to be used included a normality estimation analysis through the KolmogorovSmirnov test, customising in its case and in function of its results the appropriate test of averages (Student's T or U-Mann-Whitney-Wilcoxon) to compare both groups. The whole statistical analysis was developed with the statistical package SPSS v15.0.1 for Windows 8 pro.

\section{RESULTS}

From the analysis carried out to determine the normality of the obtained values through a non-parametric KS-1 test in SPSS, it was revealed that only the cholesterol was above ' 05 ( $p>0$ ' 05 ), fulfilling the normality criteria with which we were able to carry out an inferential evaluation or Student's T. On the contrary, in the case of the triglycerides and glucose in the blood, the null hypothesis is rejected, so the non-parametric Wilcoxon test was carried out to contrast paired data.

\section{On the glucose in the blood before and after the intervention}

For the variable analysis a different way was used since the normality criteria was not achieved, so for the glucose in the blood variable a Wilcoxon signed-ranked test was carried out in which, as can be seen in Table 1 , the bilateral asymptotic significance is inferior to 0,05 . An archive segmentation is carried out to see in what measure do the variables of gender and school year affect the glucose in the blood. As can be seen in Tables 2 and 3 , in the case of gender in the first table, there are significant differences between boys and girls; and, in the case of school years, there are significant differences in the Primary Education group and in the Secondary Education grpoup, not being this the same for the Pre-School group.

Table 1. Contrast statistics.

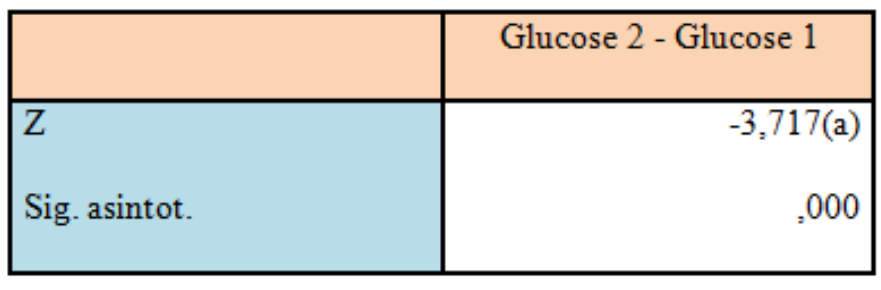

\section{On the triglycerides before and after the intervention}

The same procedure as the previous variable was used to measure the triglycerides since it was not possible to opt for the null hypothesis and the Wilcoxon test was carried out, obtaining as a result that there were not significant differences between the pretest and posttest, as can be seen in Table 4. Neither there were significant differences in any of the segmentations done to differentiate between boys and girls as can be observed in Table 5, and neither dividing the sample by school stages (Pre-School, Primary and Secondary Education), as can be seen in Table 6. 
Table 2. Contrast statistics by gender

\begin{tabular}{|ll|r|}
\hline SEX & & Glucose 2 - Glucose 1 \\
\hline 1 & Z & $-2,488(\mathrm{a})$ \\
& Sig. asintot. &, 013 \\
2 & Z & $-2,802(\mathrm{a})$ \\
& Sig. asintot. &, 005 \\
\hline
\end{tabular}

Table 3. Contrast statistics by school year

\begin{tabular}{|ll|r|}
\hline Pre-school / Primary / Secondary & Glucose 2 - Glucose 1 \\
\hline 1 & Z &,$- 655(\mathrm{a})$ \\
& Sig. asintot. &, 513 \\
2 & Z & $-3,159(\mathrm{a})$ \\
& Sig. asintot. &, 002 \\
3 & Z & $-2,092(\mathrm{a})$ \\
& Sig. asintot. &, 036 \\
\hline
\end{tabular}

Table 4. Contrast statistics

\begin{tabular}{|l|r|}
\hline & Triglycerides 2 - Triglycerides 1 \\
\hline Z &,- 957 (a) \\
Sig. asintot. &, 339 \\
\hline
\end{tabular}

Table 5 . Contrast statistics by gender

\begin{tabular}{|ll|r|}
\hline SEX & & Triglycerides 2 - Triglycerides 1 \\
\hline 1 & Z &,$- 126(\mathrm{a})$ \\
& Sig. asintot. &, 900 \\
2 & Z & $-1,161(\mathrm{a})$ \\
& Sig. asintot. &, 246 \\
\hline
\end{tabular}

Table 6. Contrast statistics by school year

\begin{tabular}{|ll|r|}
\hline Pre-school / Primary / Secondary & Triglycerides 2 - Triglycerides 1 \\
\hline 1 & Z & $-1,917(\mathrm{a})$ \\
& Sig. asintot. &, 055 \\
& Z &,$- 539(\mathrm{~b})$ \\
& Sig. asintot. &, 590 \\
3 & Z & $-1,193(\mathrm{a})$ \\
& Sig. asintot. &, 233 \\
\hline
\end{tabular}




\section{DISCUSSION}

We aim to discuss the results of this study contrasting them with other research with similar characteristics, which have previously proven that physical activity is beneficial for health because it reduces cardiovascular risk factors. In addition, their authors observed that applying interventions on children and teenagers can improve the values of the parameters which indicate the state of health and prevent and reduce diseases like obesity (Snyder et al., 1999).

It has been pointed out that an altered lipid profile is associated to early atherogenesis and the risk of suffering from hypertension (Garcia-Artero et al., 2007), in the same way that it is associated to multiple diseases and comorbidities (Dietz, 1998, 2001; Haslam \& James, 2005). Consequently and in the search for solutions, multiple studies have brought to light that increasing physical activity and its intensity are associated with an improvement in the health parameters of this profile (García-Artero et al., 2007; Ruiz, Ortega, Warnberg, \& Sjostrom, 2007), even though, for these studies, the triglycerides exhibited significantly lower values than in the present study.

In spite of this, the data taken from the present study goes along these lines, since the analysis of fasting glucose shows significant improvements in its values after the physical activity intervention program. This coincides with what was established by other researchers who already proved that it was necessary to increase the amount of vigorous-to-intense physical activity because of the beneficial effects it has on health, such as reducing risk factors, decreasing the amount of fat, improving the lipid profile and improving physical fitness along with increasing the maximum oxygen consumption (Lobelo, Pate, Dowda, Liese \& Ruiz, 2009; Ortega et al., 2005).

As has been shown in the theoretical explanation, metabolic syndrome in children can be diagnosed with abdominal obesity and the presence of two or more clinical manifestations. Thus, the parameter values of triglycerides and glucose in the blood deserve special consideration because the level of physical activity which is practiced will be a determining factor for these. This is an important fact since it is directly associated with insulin resistance, understanding the positive contribution this has on the lipoprotein metabolism and an increase of lipolysis in the adipose tissue (Riemens, Van Tol, Scheek, \& Dullaart, 2001). As a consequence, the $\mathrm{AHA}$, recommends determining the values of fasting glucose to evaluate the risk of infant insulin resistance, especially in girls with early menarche, due to the tendency of excess weight and the consequent increase in cardiovascular risk (Steinberger \& Daniels, 2003).

Considering what has been mentioned up until now, it is necessary to consider the gender variable as a possible element which might affect the results of the subjects who are the object of this study, along with the age or age group variable because of its amplitude in the current research. Furthermore, it is easy to understand why physical fitness is evaluated and connected in multiple studies with certain indicative health parameters, since it not only allows to improve these values, but it is also understood as an indicator, not only of the state of fitness, but also of the state of health because of the direct association between them (Ekelund et al., 2001; Myers et al, 2002).

\section{On gender and school year before and after the intervention}

From the results taken from the present study, we can observe that both girls and boys obtained significant results for the glucose in the blood variable, yet this is not the same for the triglycerides parameter in which neither was able to reduce the values significantly. These results, for both girls and boys, in terms of 
alterations in the lipid profile had already been consolidated and are in agreement with those taken from studies carried out by other authors (Garcia-Artero et al., 2007; Moliner, Urdiales et al., 2010).

However, the present study also hopes to learn in what measure the improvement might be influenced by the school phase in which our subjects are, potraying the results that, in Primary and Secondary Education, there were significant improvements for fasting glucose, but not for triglycerides like in the previous cases. Likewise, these improvements were not significant for the Pre-School stage in none of the parameters. For that matter, one of the main lines in which many studies are developed is the connection between sedentariness and low physical fitness and a low state of health in children and teenagers, specifically in the ages of Primary and Secondary Education (Dumith \& Farias, 2010; Ekelund et al., 2006; Goran, 2001; Ochoa et al., 2007). The justification which is given in many occassions is the presence of new technologies and the excessive consumption of certain electronic devices, television and game consoles (Ekelund et al., 2006).

On this basis, it is easier to understand that during the ages of Primary and Secondary Education, in which the consumption of these devices begins, a physical activity program can improve the health of the subjects; not being the same for earlier ages in which they are not as inmersed in the technological world and the need and restlessness to learn and discover new things leads them to be in constant movement (Fisher et al., 2005). Physical inactivity, as a determining factor for the state of health, is the result of this progressive change of lifestyle, in developed countries, towards more sedentary patterns. The results of this study show a direct association between the practice of vigorous-to-intense physical activity and the reduction of cardiovascular risk factors, which shows the importance of children's exercise to prevent excess weight and obesity, along the lines of other studies which associated the increase of metabolic syndrome with inactivity (Ella, Shehab, Ismail \& Maksoud, 2010; Jimenez-Pavon et al., 2013).

For this reason, the improvement of cardiovascular fitness in childhood and adolescence is essential for the further adherence to regular physical activity in adulthood (Leary et al., 2008).

\section{CONCLUSIONS}

With regard to each of the intended objectives and after carrying out the analysis, for the present study we can conclude that:

- A physical activity intervention program through vigorous-to-intense games three times a week, 10 minutes per session, obtains improvements in the lipid profiles of the subjects of the study, in terms of the glucose in the blood parameter which is a health indicator.

- No improvements were obtained in the values of the triglycerides parameter.

- The gender variable does not affect the improvement of the fasting glucose or triglyerides variables.

- The opposite to what happens with gender happens with the age or school year variable, since the subjects belonging to Primary or Secondary Education groups obtained improvements in the values of fasting glucose, something that did not happen with the children in Pre-School Education.

Therefore, it is concluded that intervalic physical activity practiced regularly and at high intensities leads to a reduction in the risk of suffering alterations in the biochemical profile, which are associated to certain cardiovascular diseases and those derived or consequent to these, like obesity. This is why enhancing physical activity in the early years, should be valued as a factor to have in consideration for the health of the individual, since, as can be observed from the study, it can produce positive effects. 
Moreover, as has been explained earlier, obesity is a disease which is very present in current society starting from childhood, which is why the benefits that physical activity can produce as early preventive measures is something to be considered in the life of these individuals; because of the positive effect it can produce in the risk profile of subjects with this disease. Thus, it is necessary to carry out future studies of a longitudinal character with a larger sample and an experimental proposal, like in the present study, where it would be possible to widen the number of participants per age group and obtain values comparing them, even with control groups.

In addition, it is important to encourage the practice of physical activity given the emergent problem which is sedentariness nowadays as a consequence of the consumption of new technologies, especially beginning in Primary Education. For this it is necessary to help children and teenagers to see physical activity as something positive and attractive through programs in which they work out intensely through games, like in the present study, so that at the same time they obtain the health benefits of this, obtaining it as a fun and leisure alternative different to other more sedentary activities.

\section{REFERENCES}

Carnethon, M. R., Gidding, S. S., Nehgme, R., Sidney, S., Jacobs, D. R., \& Liu, K. (2003). Cardiorespiratory fitness in young adulthood and the development of cardiovascular disease risk factors. Jama-Journal of the American Medical Association, 290(23), 3092-3100. https://doi.org/10.1001/jama.290.23.3092

Caspersen, C. J., Powell, K. E., \& Christenson, G. M. (1985). Physichal-activity, exercise and physicalfitness. Definitions and distinctions for health-related research. Public Health Reports, 100(2), 126131.

Cleeman, J. I., Grundy, S. M., Becker, D., Clark, L. T., Cooper, R. S., Denke, M. A., et al. (2001). Executive summary of the Third Report of the National Cholesterol Education Program (NCEP) expert panel on detection, evaluation, and treatment of high blood cholesterol in adults (Adult Treatment Panel III). Jama-Journal of the American Medical Association, 285(19), 2486-2497. https://doi.org/10.1001/jama.285.19.2486

Costa, G. B., Horta, N., Resende, Z. F., Souza, G., Barreto, L. M. D., Correia, L. H., et al. (2009). Body Mass Index Has a Good Correlation with Proatherosclerotic Profile in Children and Adolescents. Arquivos Brasileiros De Cardiologia, 93(3), 261-267. https://doi.org/10.1590/S0066$\underline{782 \times 2009000900010}$

Damasceno, M. M. C., Lopes, M. V. D., Oliveira, D. D., Nogueira, N. P., Siqueira, I. D., \& de Macedo, S. F. (2009). Obesity among public school teenagers: the performance of three anthropometric criteria. Acta Paulista De Enfermagem, 22(2), 198-204. https://doi.org/10.1590/S0103-21002009000200013

Dietz, W. H. (1998). Health consequences of obesity in youth: Childhood predictors of adult disease. Pediatrics, 101(3), 518-525.

Dietz, W. H. (2001). Overweight and precursors of type 2 diabetes mellitus in children and adolescents. Journal of Pediatrics, 138(4), 453-454. https://doi.org/10.1067/mpd.2001.113635

Dumith, S. C., \& Farias, J. C. (2010). Overweight and obesity in children and adolescents: comparison of three classification criteria based on body mass index. Revista Panamericana De Salud PublicaPan American Journal of Public Health, 28(1), 30-35. https://doi.org/10.1590/S1020$\underline{49892010000700005}$

Eaton, D. K., Kann, L., Kinchen, S., Ross, J., Hawkins, J., Harris, W. A., et al. (2006). Youth risk behavior surveillance - United States, 2005. Journal of School Health, 76(7), 353-372. https://doi.org/10.1111/i.1746-1561.2006.00127.x 
Ekelund, U., Brage, S., Froberg, K., Harro, M., Anderssen, S. A., Sardinha, L. B., et al. (2006). TV viewing and physical activity are independently associated with metabolic risk in children: The European Youth Heart Study. Plos Medicine, 3(12), 2449-2457. https://doi.org/10.1371/journal.pmed.0030488

Ekelund, U., Poortvliet, E., Nilsson, A., Yngve, A., Holmberg, A., \& Sjostrom, M. (2001). Physical activity in relation to aerobic fitness and body fat in 14-to 15-year-old boys and girls. European Journal of Applied Physiology, 85(3-4), 195-201. https://doi.org/10.1007/s004210100460

Ella, N. A. A., Shehab, D. I., Ismail, M. A., \& Maksoud, A. A. (2010). Prevalence of metabolic syndrome and insulin resistance among Egyptian adolescents 10 to 18 years of age. Journal of Clinical Lipidology, 4(3), 185-195. https://doi.org/10.1016/j.jacl.2010.03.007

Fagot-Campagna, A., Pettitt, D. J., Engelgau, M. M., Burrows, N. R., Geiss, L. S., Valdez, R., et al. (2000). Type 2 diabetes among North American children and adolescents: An epidemiologic review and a public health perspective. Journal of Pediatrics, 136(5), 664-672. https://doi.org/10.1067/mpd.2000.105141

Fisher, A., Reilly, J. J., Kelly, L. A., Montgomery, C., Williamson, A., Paton, J. Y., et al. (2005). Fundamental movement skills and habitual physical activity in young children. Medicine and Science in Sports and Exercise, 37(4), 684-688. https://doi.org/10.1249/01.MSS.0000159138.48107.7D

Garcia-Artero, E., Ortega, F. B., Ruiz, J. R., Mesa, J. L., Delgado, M., Gonzalez-Gross, M., et al. (2007). Lipid and metabolic profiles in adolescents are affected more by physical fitness than physical activity (AVENA study). [Article]. Revista Espanola De Cardiologia, 60(6), 581-588.

Giralt, M., Albaladejo, R., Tarro, L., Morina, D., Arija, V., \& Sola, R. (2011). A primary-school-based study to reduce prevalence of childhood obesity in Catalunya (Spain) - EDAL-Educacio en alimentacio: study protocol for a randomised controlled trial. Trials, 12. https://doi.org/10.1186/1745-6215-12-54

Goran, M. I. (2001). Metabolic precursors and effects of obesity in children: a decade of progress, 19901999. American Journal of Clinical Nutrition, 73(2), 158-171. https://doi.org/10.1093/ajcn/73.2.158

Grunbaum, J. A., Kann, L., Kinchen, S. A., Williams, B., Ross, J. G., Lowry, R., et al. (2002). Youth risk behavior surveillance - United States, 2001. Journal of School Health, 72(8), 313-328. https://doi.org/10.1111/j.1746-1561.2002.tb07917.x

Haslam, D. W., \& James, W. P. T. (2005). Obesity. [Review]. Lancet, 366(9492), 1197-1209. https://doi.org/10.1016/S0140-6736(05)67483-1

Jimenez-Pavon, D., Konstabel, K., Bergman, P., Ahrens, W., Pohlabeln, H., Hadjigeorgiou, C., et al. (2013). Physical activity and clustered cardiovascular disease risk factors in young children: a crosssectional study (the IDEFICS study). Bmc Medicine, 11. https://doi.org/10.1186/1741-7015-11-172

Leary, S. D., Ness, A. R., Smith, G. D., Mattocks, C., Deere, K., Blair, S. N., et al. (2008). Physical activity and blood pressure in childhood - Findings from a population-based study. Hypertension, 51(1), 9298. https://doi.org/10.1161/HYPERTENSIONAHA.107.099051

Lobelo, F., Pate, R. R., Dowda, M., Liese, A. D., \& Ruiz, J. R. (2009). Validity of Cardiorespiratory Fitness Criterion-Referenced Standards for Adolescents. Medicine and Science in Sports and Exercise, 41(6), 1222-1229. https://doi.org/10.1249/MSS.0b013e318195d491

McGill, H. C. (1990). Relationship of atherosclerosis in young men to serum-lipoprotein cholesterol concentrations and smoking. A prelliminary report from the pathobiological determinants of atherosclerosis in youth (PDAY) research group. Jama-Journal of the American Medical Association, 264(23), 3018-3024. https://doi.org/10.1001/jama.1990.03450230054029

McGill, H. C., McMahan, C. A., Herderick, E. E., Tracy, R. E., Malcom, G. T., Zieske, A. W., et al. (2000). Effects of coronary heart disease risk factors on atherosclerosis of selected regions of the aorta and right coronary artery. Arteriosclerosis Thrombosis and Vascular Biology, 20(3), 836-845. https://doi.org/10.1161/01.ATV.20.3.836 
McGill, H. C., McMahan, C. A., Zieske, A. W., Sloop, G. D., Walcott, J. V., Troxclair, D. A., et al. (2000). Associations of coronary heart disease risk factors with the intermediate lesion of atherosclerosis in youth. Arteriosclerosis Thrombosis and Vascular Biology, 20(8), 1998-2004. https://doi.org/10.1161/01.ATV.20.8.1998

McGovern, L., Johnson, J. N., Paulo, R., Hettinger, A., Singhal, V., Kamath, C., et al. (2008). Treatment of Pediatric Obesity: A Systematic Review and Meta-Analysis of Randomized Trials. Journal of Clinical Endocrinology \& Metabolism, 93(12), 4600-4605. https://doi.org/10.1210/ic.2006-2409

Moliner-Urdiales, D., Ruiz, J. R., Ortega, F. B., Jimenez-Pavon, D., Vicente-Rodriguez, G., Rey-Lopez, J. P., et al. (2010). Secular trends in health-related physical fitness in Spanish adolescents The AVENA and HELENA Studies. Journal of Science and Medicine in Sport, 13(6), 584-588. https://doi.org/10.1016/.j.jsams.2010.03.004

Morris, J. N., Pollard, R., Everitt, M. G., Chave, S. P. W., \& Semmence, A. M. (1980). Vigorous exercise in leisure time. Protection against coronary heart disease. Lancet, 2(8206), 1207-1210. https://doi.org/10.1016/S0140-6736(80)92476-9

Must, A., Jacques, P. F., Dallal, G. E., Bajema, C. J., \& Dietz, W. H. (1992). Long term mobidity and mortality of overweight adolescents. A follw up of the harvard growth study of 1922 to 1935. New England Journal of Medicine, 327(19), 1350-1355. https://doi.org/10.1056/NEJM199211053271904

Myers, J., Prakash, M., Froelicher, V., Do, D., Partington, S., \& Atwood, J. E. (2002). Exercise capacity and mortality among men referred for exercise testing. New England Journal of Medicine, 346(11), 793-801. https://doi.org/10.1056/NEJMoa011858

Ochoa, M. C., Moreno-Aliaga, M. J., Martinez-Gonzalez, M. A., Martinez, J., Marti, A., \& Members, G. (2007). Predictor factors for childhood obesity in a Spanish case-control study. Nutrition, 23(5), 379384. https://doi.org/10.1016/j.nut.2007.02.004

Ortega, F. B., Ruiz, J. R., Castillo, M. J., Moreno, L. A., Gonzalez-Gross, M., Warnberg, J., etal. (2005). Low level of physical fitness in Spanish adolescents. Relevance for future cardiovascular health (AVENA study). Revista Espanola De Cardiologia, 58(8), 898-909. https://doi.org/10.1157/13078126

Pate, R. R., Corbin, C. B., Simonsmorton, B. G., \& Ross, J. G. (1987). Phisichal education and its role in school health promotion. Journal of School Health, 57(10), 445-450. https://doi.org/10.1111/j.17461561.1987.tb03191.x

Riemens, S. C., Van Tol, A., Scheek, L. M., \& Dullaart, R. P. F. (2001). Plasma cholesteryl ester transfer and hepatic lipase activity are related to high-density lipoprotein cholesterol in association with insulin resistance in type 2 diabetic and non-diabetic subjects. Scandinavian Journal of Clinical \& Laboratory Investigation, 61(1), 1-9. https://doi.org/10.1080/00365510151067866

Ries, A. V., Voorhees, C. C., Gittelsohn, J., Roche, K. M., \& Astone, N. M. (2008). Adolescents' perceptions of environmental influences on physical activity. American Journal of Health Behavior, 32(1), 26-39. https://doi.org/10.5993/AJHB.32.1.3

Romero-Velarde, E., Campollo-Rivas, O., de la Rosa, A. C., Vasquez-Garibay, E. M., Castro-Hernandez, J. F., \& Cruz-Osorio, R. M. (2007). Risk factors for dislypidemia in obese children and adolescents. Salud Publica De Mexico, 49(2), 103-108. https://doi.org/10.1590/S0036-36342007000200005

Ruiz, J. R., Ortega, F. B., Warnberg, J., \& Sjostrom, M. (2007). Associations of low-grade inflammation with physical activity, fitness and fatness in prepubertal children; the European Youth Heart Study. International Journal of Obesity, 31(10), 1545-1551. https://doi.org/10.1038/sj.ijo.0803693

Seidell, J. C., \& Flegal, K. M. (1997). Assessing obesity: Classification and epidemiology. [Article]. British Medical Bulletin, 53(2), 238-252. https://doi.org/10.1093/oxfordjournals.bmb.a011611

Shephard, R. J., \& Bouchard, C. (1994). Population evaluations of health related fitness from perceptions of physical activity and fitness. Canadian Journal of Applied Physiology-Revue Canadienne De Physiologie Appliquee, 19(2), 151-173. https://doi.org/10.1139/h94-012 
Shephard, R. J., \& Bouchard, C. (1995). Relationship between perceptions of physical activity and healthrelated fitness. Journal of Sports Medicine and Physical Fitness, 35(3), 149-158.

Snyder, P., Anliker, J., Cunningham-Sabo, L., Dixon, L. B., Altaha, J., Chamberlain, A., et al. (1999). The Pathways study: a model for lowering the fat in school meals. American Journal of Clinical Nutrition, 69(4), 810S-815S. https://doi.org/10.1093/ajcn/69.4.810S

Steinberger, J., \& Daniels, S. R. (2003). Obesity, insulin resistance, diabetes, and cardiovascular risk in children - An American Heart Association scientific statement from the Atherosclerosis, Hypertension, and Obesity in the Young Committee (Council on Cardiovascular Disease in the Young) and the Diabetes Committee (Council on Nutrition, Physical Activity, and Metabolism). Circulation, 107(10), 1448-1453. https://doi.org/10.1161/01.CIR.0000060923.07573.F2

Van Sluijs, E. M. F., van Poppel, M. N. M., \& van Mechelen, W. (2004). Stage-based lifestyle interventions in primary care - Are they effective? American Journal of Preventive Medicine, 26(4), 330-343. https://doi.org/10.1016/j.amepre.2003.12.010

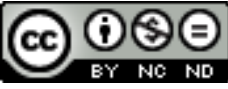

This title is licensed under a Creative Commons Attribution-NonCommercial-NoDerivs 4.0 Unported License. 